\title{
Integrated project task and manpower scheduling
}

\author{
HESHAM K. ALFARES ${ }^{1}$ and JAMES E. BAILEY ${ }^{2}$ \\ ${ }^{1}$ King Fahd University of Petroleum and Minerals, Dhahran 31261, Saudi Arabia \\ ${ }^{2}$ Arizona State University, Tempe, AZ 85287-5906, USA
}

Received July 1993 and accepted September 1995

\begin{abstract}
The objective of project task scheduling is to determine task start dates and durations to complete a project on time with the minimum cost of performing tasks plus overhead. By altering task start dates and durations, the daily labor-demand profile can be changed. The objective of personnel scheduling is to determine how many workers must be assigned to each feasible days-off tour to satisfy a given labor-demand profile with minimum labor cost. Integrating these two problems permits the simultaneous determination of start dates, durations, labor levels and required tours for a minimum-cost and on-time schedule. Both integer programming and heuristic solution procedures to solve the integrated problem are presented. In a series of 20 test problems, the heuristic procedure outperformed the traditional two-step scheduling procedure by reducing the cost of labor and overhead by $8.6 \%$.
\end{abstract}

\section{Introduction}

Among the major sectors of the American economy, construction is valued in excess of $\$ 418$ billion annually [1]. Productivity in that industry has been consistently declining since the 1960s, which has resulted in a competitive disadvantage for U.S. firms [2]. During the 1980s, international contracts for U.S. firms dropped by nearly half, whereas foreign competitors increased their share of U.S. contracts by a factor of three [1]. To regain the competitive edge, American construction companies must adopt higher quality standards and improved management practices. Labor, which accounts for $40 \%$ of a construction project's cost, must not be wasted.

At present, the absence of any published integrated model indicates that project task and manpower scheduling are accomplished in two sequential steps. A project scheduling algorithm first determines the start time and duration, which is a function of labor level, for each task. These results establish a daily labor-demand profile, which is then used by a manpower scheduling algorithm to determine the number of workers assigned to feasible days-off tours. A weekly days-off tour is defined as a set of five work days and two consecutive off days; there are seven such sets for any week.

Fixing the task schedule before solving the labor scheduling problem leads to sub-optimal solutions. Clearly, when each task starts, how much labor is assigned to it, and how long it is active, affect the labordemand profile for the project. That profile, in turn, constrains the labor scheduling problem. Therefore to determine the minimum cost schedule one should integrate the task and labor scheduling problems.

This paper presents an integer linear programming (ILP) optimization procedure for the integration of these two scheduling problems. The paper also presents a heuristic procedure that performs nearly as well. For 20 test problems, the ILP procedure outperformed the twostep procedure with an average $9.1 \%$ reduction in the cost of labor plus overhead. The heuristic procedure outperformed the traditional two-step procedure in every test case with an average total cost reduction of $8.6 \%$. The heuristic procedure yielded the same solution as the optimization procedure in 10 of the 20 test problems, with an overall average cost increase of only $0.57 \%$ above the optimal solution. Cost comparisons for the 20 test problems are shown in Tables 2 and 3.

Integer linear programming models for project scheduling have been presented by many authors [3-8]. Dynamic programming formulations of the project scheduling problem were developed by Petrovic [9] and Davis and Heidorn [10]. Branch-and-bound algorithms for this problem are presented by Stinson et al. [11] and by Talbot and Patterson [12]. A goal programming model was formulated by Lee and Olson [13]. None of these formulations consider alternative day-off tours as a means of reducing total labor cost.

Baker [14, 15] first formulated the cost-minimizing ILP model of the manpower scheduling problem, and developed an algorithm for solving this problem with two consecutive days off per week for each tour. Bartholdi et al. [16-18] developed techniques using continuous LP for solving this integer-valued manpower scheduling 
problem. Others have extended Baker's model [19-22] by analyzing different variations of the problem. None of the personnel scheduling models explored ways to change the demand profile to reduce the cost of labor. There are no published papers on ways to integrate the two aspects of this problem.

\section{Integrated ILP project and manpower scheduling model}

As with other project scheduling models, the objective (1) of the integrated model shown below is to minimize the sum of overhead plus labor costs. There are five sets of constraints in the model. The first set of constraints (2) ensures that a unique duration and start date be chosen for each task in the final solution. The second set of constraints (3) requires that the start date of any task be later than the completion date of all its immediate predecessors. The third set of constraints (4) guarantees that the number of people assigned to work any given day is at least equal to the summed manpower demand of all tasks scheduled for that day. This is the constraint that integrates the personnel scheduling and the project scheduling models. The fourth set of constraints (5) sets the project duration time as the completion of the last task from the set of tasks with no successors. A last set of constraints (6) limits the total work force size in any given week.

The integer linear programming model is therefore:

$$
\text { Minimize COST }=O H \times P T+\sum_{w=1}^{N W K} \sum_{i=1}^{7} C_{i} \times Y_{w i}
$$

Subject to

$$
\begin{gathered}
\sum_{d=E S_{j}}^{L S_{j t}} \sum_{\forall t \in T_{j}} X_{j d t}=1, \quad j=1, \ldots, N A C T \\
\sum_{d=E S_{p}}^{L S_{p t}} \sum_{\forall t \in T_{p}}(d+t) \times X_{p d t} \leq \sum_{d=E S_{j}}^{L S_{j t}} \sum_{\forall t \in T_{j}} d \times X_{j d t} \\
\forall p \in P_{j}, j=1, \ldots, N A C T \\
\sum_{j=1}^{N A C T} \sum_{\forall t \in T_{j}} \sum_{q=\max \left(d-t+1, E S_{j}\right)}^{\min \left(d, L S_{j t}\right)} \\
\sum_{d=E S_{j}} \sum_{\forall t \in N_{j}}\left(d+t=1, \ldots, T U ; X_{j d t} \leq \sum_{w=1}^{N W K} \sum_{i=1}^{7} a a_{w i d} \times Y_{w i},\right. \\
\sum_{i=1}^{7} Y_{w i} \leq S I Z E_{w}, \quad w=1, \ldots, N W K
\end{gathered}
$$

where

$$
\begin{aligned}
a a_{w i d}= & \begin{cases}1 \quad & \text { if day } d \text { is a work day for days-off } \\
\text { tour } i \text { in week } w, \\
0 \quad & \text { otherwise } ;\end{cases} \\
C_{i}= & \text { weekly cost of days-off tour } i \\
d= & \text { start day of task } j \\
E S_{j}= & \text { earliest possible start date for activity } j \\
L= & \text { set of all tasks which have no successors } \\
L S_{j t}= & \text { latest possible start date for activity } j \\
& \text { if it has a duration of } t \\
M A N_{j t}= & \text { daily required manpower for task } j \\
& \text { if its duration is } t \\
& t \times M A N_{j t} \geq T M A N_{j}
\end{aligned}
$$

$N A C T=$ the number of tasks in the project;

$N W K=$ project due date in weeks;

$\mathrm{OH}=$ daily overhead cost;

$p=$ an immediate predecessor of task $j,\left(p \in P_{j}\right)$;

$P_{j}=$ set of immediate predecessors for task $j$;

$P T=$ project duration in days, $P T \geq 0$ and integer;

$S I Z E_{w}=$ maximum size of the work force in week $w$;

$t=$ time duration in days of task $j,\left(t \in T_{j}\right)$;

$T_{j}=$ the set of activity duration times for activity $j$;

$T M A N_{j}=$ total man-days of effort required by task $j ;$

$T U=$ project due date, or maximum project duration in days;

$$
\begin{aligned}
X_{j d t}= & \begin{cases}1 & \text { if task } j \text { with duration time } t \text { is } \\
\text { started on day } d & \end{cases} \\
0 & \text { otherwise } ;
\end{aligned}
$$

\section{Heuristic solution procedure}

A big limitation for the ILP solution procedure is that the required number of constraints and variables make the procedure too slow and costly for realistic problems. For example, the largest problem that could be solved within 120 CPU seconds on an IBM 3090 mainframe computer involved only 15 tasks, but needed 60 constraints and 69 integer variables. Because the ILP procedure is unable to solve larger problems in a reasonable amount of time, a heuristic procedure is obviously needed for practical use. The proposed heuristic uses dynamic programming (DP) to significantly reduce the complexity of large practical problems, by replacing them with much smaller and simpler weekly sub-problems. 
Because the manpower scheduling problem is solved on a week-by-week basis, it is natural to break the project scheduling problem into a sequence of linked weekly subproblems. In any week, all tasks can be placed into one of three sets: the completed-task set, the future-task set, and the active-task set containing all tasks not in one of the first two sets. A task may appear several times in a set, once for every start-time, labor-level/duration-time possibility.

Each week has a finite set of possible project schedules defined by all feasible combinations of tasks in the activetask set. Each project schedule defines a labor-demand profile that can be used to find an optimal solution by using any personnel scheduling formulation. The solution to a week's project/personnel scheduling problem is defined as a possible state for that week. In dynamic programming terminology the optimal schedule for the present and future weeks can be found when the possible states of the project at the end of the previous week are known, without regard to how one got to those states. The recursive relationship that links week $w$ to the previous weeks is given by:

$$
\begin{aligned}
\operatorname{COST}_{0}(0) & =0 ; \\
\operatorname{COST}_{w}(S) & =\operatorname{SOLN}_{w}(S)+\min \left\{\operatorname{COST}_{w-1}(C S)\right\}, \\
w & =1,2, \ldots, N W K
\end{aligned}
$$

where

$$
\begin{aligned}
\operatorname{COST}_{w}(S)= & \text { minimum cumulative cost for weeks } 1 \\
& \text { through } w \text { given state } S \text { in week } w \\
\operatorname{SOLN}_{w}(S)= & \text { the solution of the LP personnel scheduling } \\
& \text { problem with a labor demand profile for } \\
& \text { state } \mathrm{S} \text { in week } w \\
C S= & \text { the set of all solutions for week } w-1 \text { that } \\
& \text { are precedent compatible with state } S \text { in } \\
& \text { week } w .
\end{aligned}
$$

The problem is that even with DP, the number of feasible project schedules for each week can still be quite large. A procedure is needed to reduce the size of these sets. Two logical procedures can be employed. First, to be considered further, the daily labor demand should lie between two previously established limits so that labor expenditure is reasonably level during the project. The two limits are based on the average daily labor required to complete the project between the minimum critical path time $(T L)$ and due date time $(T U)$. These bounds, given below, can be arbitrarily adjusted by a factor $\alpha$, which for the test cases reported below was set at 0.3 . Increasing the value of $\alpha$ allows more weekly schedules to be considered, increasing the probability of obtaining an optimal solution, but prolonging the computation time.

$$
M i n L=\left\lfloor(1-\alpha) \sum_{j=1}^{N A C T} \min \left\{M A N_{j t}: \forall t \in T_{j}\right\} / T U\right\rfloor ;
$$

$$
M a x L=\left\lceil(1+\alpha) \sum_{j=1}^{N A C T} \max \left\{M A N_{j t}: \forall t \in T_{j}\right\} / T L\right\rceil ;
$$

where

$$
\begin{aligned}
\lfloor x\rfloor & =\text { the greatest integer smaller than } x ; \\
\lceil x\rceil & =\text { the smallest integer greater than } x ; \\
\alpha & =\text { an arbitrary factor set at } 0.3 \text { in this report. }
\end{aligned}
$$

A second size reduction procedure also employs a bound on the daily number of workers. Baker [14] presented a procedure for establishing the minimum staff size needed to satisfy a given weekly labor-demand profile. To be considered further, the work force requirement must be equal to the Baker minimum $N W F$. Given daily labor demands for one work week $R E Q_{1}, \ldots, R E Q_{7}$, Baker's algorithm to calculate $N W F$, slightly modified by Alfares [23], proceeds as follows.

Calculate initial workforce size $W=\max \left\{\left\lceil\frac{1}{5} \sum_{d=1}^{7} R E Q_{d}\right\rceil\right.$, $\left.R E Q_{\max }\right\}$.

Calculate labor slack $t=5 \mathrm{~W}-\sum_{d=1}^{7} R E Q_{d}$.

Calculate initial days-off tour assignments $Y_{1}, \ldots, Y_{7}$ as

$$
\begin{aligned}
Y_{7} & =R E Q_{2}+R E Q_{4}+R E Q_{6}-2 W \\
Y_{i} & =W-R E Q_{i+1}-Y_{i+1}, i=6,5, \ldots, 1 .
\end{aligned}
$$

Baker's bound on workforce size $N W F=W+\max$ $\left\{0,\left\lceil\frac{1}{3}\left(-Y_{\min }-t\right)\right\rceil\right\}$.

For each surviving weekly project schedule, the LP personnel scheduling formulation given below is solved. If a feasible solution is not found with this model, the weekly project schedule is discarded.

$$
\text { Minimize Lcost }=\sum_{i=1}^{7} C_{i} \times Y_{i}
$$

subject to

$$
\begin{gathered}
\sum_{i=1}^{7} a_{i d} \times Y_{i} \geq R E Q_{d}, \quad d=1, \ldots, 7 \\
\sum_{i=1}^{7} Y_{i}=N W F
\end{gathered}
$$

where

$$
\begin{aligned}
& a_{i d}= \begin{cases}1 & \begin{array}{l}
\text { if day } d \text { is a work day for weekly } \\
\text { days-off tour } i
\end{array} \\
0 & \text { otherwise ; }\end{cases} \\
& C_{i}=\text { cost of employing one person on weekly } \\
& \text { days-off tour } i \text {; } \\
& N W F=\text { Baker's lower bound limit on total weekly } \\
& \text { staff size; }
\end{aligned}
$$


$R E Q_{d}=$ the labor requirement for day $d, d=1, \ldots, 7$;

$Y_{i}=$ number of workers to be assigned tour $i, Y_{i} \geq 0$ and integer.

\section{The traditional two-stage solution}

In the first stage, project tasks are scheduled by determining the start time and duration for each task. The ILP model for this stage is based on Elmaghraby's [3] resource-constrained project scheduling formulation. The objective of this model (14) is to minimize overhead plus total required man-days cost:

$$
\begin{aligned}
\text { Minimize Pcost }= & O H \times P T \\
& +L C \sum_{j=1}^{N A C T} \sum_{d=E S_{j}}^{L S_{j t}} \sum_{\forall t \in T_{j}} t \times M A N_{j t} \times X_{j d t} .
\end{aligned}
$$

This objective is subject to the same set of constraints used in the integrated ILP model representing: unique duration and start time (2), precedence (3), project completion (5), and workforce size (6); however, manpower scheduling constraints (4) are replaced by the following manpower demand constraints:

$$
\begin{array}{r}
\sum_{j=1}^{N A C T} \sum_{\forall t \in T_{j}} \sum_{q=\max \left(d-t+1, E S_{j}\right)}^{\min \left(d, L S_{j t}\right)} M A N_{j t} \times X_{j d t} \leq S I Z E_{d}, \\
d=1, \ldots, T U
\end{array}
$$

where

$L C=$ daily labor cost per worker ;

$S I Z E_{d}=$ maximum size of the work force in day $d$.

Task durations and start times, which are fixed in the first stage, define a daily labor-demand profile. The second stage assigns workers to days-off tours to satisfy this demand profile with minimum labor cost, using Baker's [15] manpower scheduling ILP model, simply defined by (11) and (12).

\section{Comparison test results}

The optimal and heuristic procedures presented here were compared with the traditional two-step scheduling approach by using 20 test problems. The size of the test problems, 6 to 15 tasks, was constrained by the severe computational limitations of the ILP optimization procedure. Besides, the use of small test problems is commonplace in literature, even when dealing with the simpler problem of scheduling project tasks only. For example, $[4,7,24]$ reported project scheduling test problems ranging from 5 to 30 tasks. Moreover, the heuristic procedure demonstrated its practical applicability by solving a realistic problem involving 200 tasks and 40 weeks in only 25.33 seconds.
Task sequencing relationships for the test problems are represented by the four network diagrams shown in Fig. 1 . Different problems represented by the same network have common number and sequencing of tasks but vary in all other data, such as task durations, labor demands, and costs. Tasks ranged from 6 to 15 , durations from 2 to 3 weeks, ILP model constraints from 29 to 60, and ILP variables from 57 to 69 . The network used, number of tasks, weeks, ILP constraints and variables, and scheduling flexibility index for each of the 20 test problems appear in Table 1. The flexibility index equals the average number of slack-time and labor-level/duration-time scheduling alternatives that a task allows.

The results of the 20 test runs are displayed in Table 2, which presents the labor cost and total project cost. Table 3 contains the percentage improvement of the optimal and heuristic procedures over the traditional twostep procedure. Note that on average, the ILP optimal procedure yielded a $9.1 \%$ reduction in total project cost and the heuristic procedure performed almost as well, yielding an $8.6 \%$ reduction. In the test cases, labor productivity for the heuristic procedure averaged $98 \%$, an increase of $14 \%$ over the traditional procedure. Note also that the heuristic procedure yielded an optimal solution
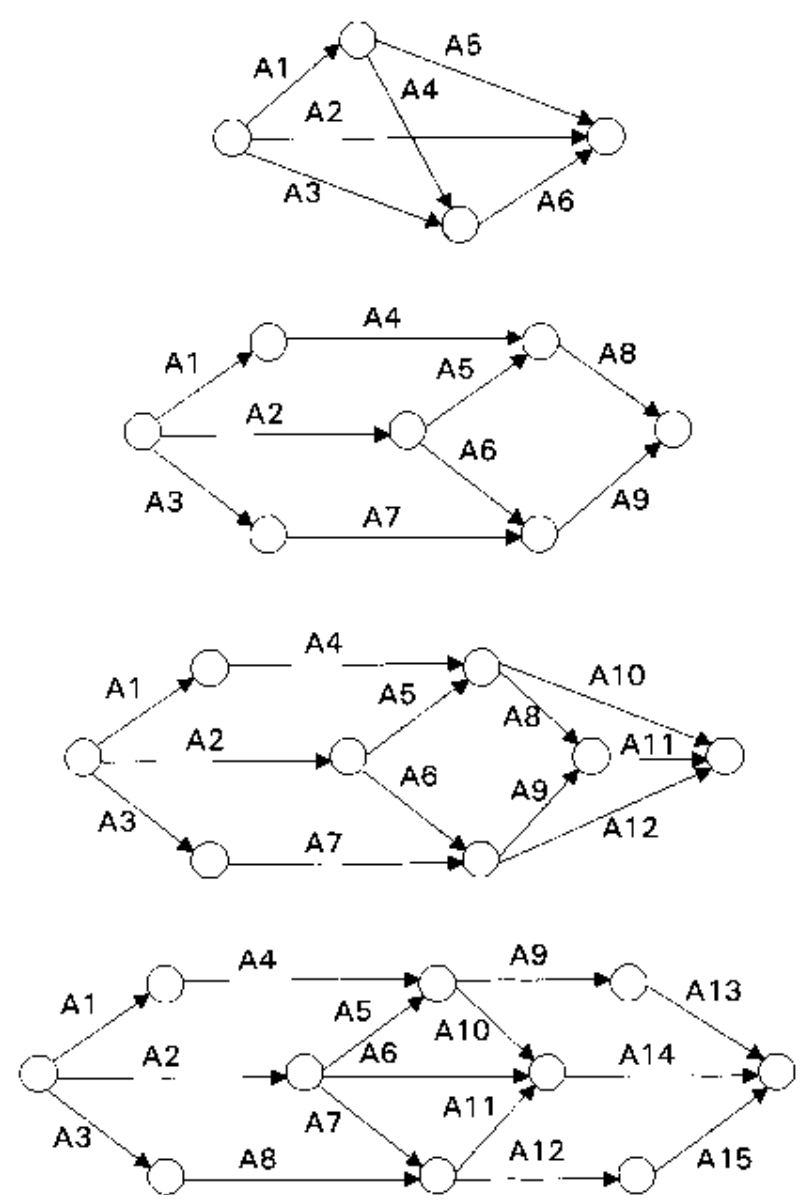

Fig. 1. Activity networks used to generate the 20 test problems. 
Table 1. Parameters of the 20 test problems including the network used, number of tasks, number of ILP constraints and variables, and flexibility index

\begin{tabular}{|c|c|c|c|c|c|c|}
\hline $\begin{array}{c}\text { Problem } \\
\text { number }\end{array}$ & $\begin{array}{c}\text { Network } \\
\text { used }\end{array}$ & $\begin{array}{l}\text { No. of } \\
\text { tasks }\end{array}$ & $\begin{array}{l}\text { No. of } \\
\text { weeks }\end{array}$ & $\begin{array}{l}\text { No. of ILP } \\
\text { constraints }\end{array}$ & $\begin{array}{l}\text { No. of ILP } \\
\text { variables }\end{array}$ & $\begin{array}{c}\text { Flexibility } \\
\text { index }\end{array}$ \\
\hline 1 & A & 6 & 2 & 29 & 65 & 8.33 \\
\hline 2 & A & 6 & 2 & 29 & 65 & 8.33 \\
\hline 3 & A & 6 & 2 & 29 & 65 & 8.33 \\
\hline 4 & A & 6 & 2 & 29 & 65 & 8.33 \\
\hline 5 & A & 6 & 2 & 29 & 57 & 7.00 \\
\hline 6 & A & 6 & 2 & 29 & 57 & 7.00 \\
\hline 7 & A & 6 & 2 & 29 & 57 & 7.00 \\
\hline 8 & A & 6 & 2 & 29 & 57 & 7.00 \\
\hline 9 & B & 9 & 2 & 35 & 65 & 5.56 \\
\hline 10 & B & 9 & 2 & 35 & 65 & 5.56 \\
\hline 11 & B & 9 & 2 & 35 & 60 & 5.00 \\
\hline 12 & B & 9 & 2 & 35 & 60 & 5.00 \\
\hline 13 & B & 9 & 2 & 35 & 60 & 5.00 \\
\hline 14 & B & 9 & 2 & 35 & 60 & 5.00 \\
\hline 15 & C & 12 & 3 & 53 & 63 & 3.42 \\
\hline 16 & $\mathrm{C}$ & 12 & 3 & 53 & 63 & 3.42 \\
\hline 17 & $\mathrm{C}$ & 12 & 3 & 53 & 63 & 3.42 \\
\hline 18 & D & 15 & 3 & 60 & 69 & 3.13 \\
\hline 19 & D & 15 & 3 & 60 & 69 & 3.13 \\
\hline 20 & $\mathrm{D}$ & 15 & 3 & 60 & 69 & 3.13 \\
\hline
\end{tabular}

in half the test cases and averaged only $0.6 \%$ higher costs than the optimal procedure. Finally, the heuristic procedure produced an average reduction of $58 \%$ in computation time compared with the optimal integer programming procedure.

As expected, all of the cost saving was in labor. In fact, in three-quarters of the test cases the integrated procedures found lower cost solutions by lengthening the project's duration while employing fewer workers. This leads to the observation that the traditional two-step scheduling procedure minimizes the project duration time and the associated overhead cost but frequently does so by using more costly labor-demand profiles. If desired, however, the heuristic procedure can be geared towards minimizing project durations by increasing the overhead cost or imposing earlier due date requirements.

The heuristic procedure's percentage savings in total cost was regressed against the scheduling flexibility index, number of ILP constraints, and number of tasks to see how these variables affected the performance of the

Table 2. Labor cost and total cost results for the 20 test problems

\begin{tabular}{|c|c|c|c|c|c|c|}
\hline $\begin{array}{l}\text { Problem } \\
\text { number }\end{array}$ & $\begin{array}{l}\text { Two-step } \\
\text { labor cost }\end{array}$ & $\begin{array}{l}\text { Heuristic } \\
\text { labor cost }\end{array}$ & $\begin{array}{c}\text { Optimal } \\
\text { labor cost }\end{array}$ & $\begin{array}{l}\text { Two-step } \\
\text { total cost }\end{array}$ & $\begin{array}{l}\text { Heuristic } \\
\text { total cost }\end{array}$ & $\begin{array}{l}\text { Optimal } \\
\text { total cost }\end{array}$ \\
\hline 1 & 3720 & 2980 & 3020 & 4920 & 4380 & 4320 \\
\hline 2 & 4620 & 3790 & 3790 & 5820 & 4990 & 4990 \\
\hline 3 & 4460 & 3740 & 3740 & 5660 & 4940 & 4940 \\
\hline 4 & 3810 & 3120 & 3080 & 4770 & 4080 & 4040 \\
\hline 5 & 3400 & 2810 & 2810 & 5800 & 5210 & 5210 \\
\hline 6 & 4890 & 4010 & 4010 & 7290 & 6410 & 6410 \\
\hline 7 & 4920 & 3910 & 3910 & 7320 & 6310 & 6310 \\
\hline 8 & 5040 & 4160 & 4160 & 7440 & 6560 & 6560 \\
\hline 9 & 4820 & 3930 & 3930 & 7020 & 6330 & 6330 \\
\hline 10 & 5700 & 4610 & 4610 & 7900 & 7010 & 7010 \\
\hline 11 & 4720 & 4020 & 3900 & 6920 & 6420 & 6300 \\
\hline 12 & 4720 & 3900 & 3900 & 6040 & 5580 & 5460 \\
\hline 13 & 5580 & 4140 & 4110 & 7780 & 6940 & 6910 \\
\hline 14 & 4550 & 4140 & 4110 & 5850 & 5540 & 5510 \\
\hline 15 & 9300 & 8390 & 8390 & 13100 & 12590 & 12590 \\
\hline 16 & 10500 & 9400 & 9400 & 14300 & 13600 & 13600 \\
\hline 17 & 10720 & 9580 & 9430 & 14520 & 13780 & 13630 \\
\hline 18 & 8170 & 7800 & 7730 & 12170 & 12000 & 11930 \\
\hline 19 & 9040 & 8670 & 8580 & 13040 & 12870 & 12780 \\
\hline 20 & 8170 & 7590 & 7420 & 11370 & 10950 & 10780 \\
\hline
\end{tabular}


Table 3. Optimal and heuristic procedures' percentage savings in total and labor cost over the two-step procedure and percentage increase in heuristic relative to optimum for the 20 problems

\begin{tabular}{|c|c|c|c|c|c|}
\hline $\begin{array}{l}\text { Problem } \\
\text { number }\end{array}$ & $\begin{array}{c}\text { Heuristic } \\
\text { labor cost } \\
\text { savings }(\%)\end{array}$ & $\begin{array}{c}\text { Optimal } \\
\text { labor cost } \\
\text { savings }(\%)\end{array}$ & $\begin{array}{c}\text { Heuristic } \\
\text { total cost } \\
\text { savings }(\%)\end{array}$ & $\begin{array}{c}\text { Optimal } \\
\text { total cost } \\
\text { savings }(\%)\end{array}$ & $\begin{array}{c}\text { Heur.lopt. } \\
\text { total cost } \\
\text { increase }(\%)\end{array}$ \\
\hline 1 & 19.89 & 18.82 & 10.98 & 12.20 & 1.39 \\
\hline 2 & 17.97 & 17.97 & 14.26 & 14.26 & 0 \\
\hline 3 & 16.14 & 16.14 & 12.72 & 12.72 & 0 \\
\hline 4 & 18.22 & 19.16 & 14.47 & 15.30 & 0.99 \\
\hline 5 & 17.35 & 17.35 & 10.17 & 10.17 & 0 \\
\hline 6 & 18.00 & 18.00 & 12.07 & 12.07 & 0 \\
\hline 7 & 20.53 & 20.53 & 13.80 & 13.80 & 0 \\
\hline 8 & 17.46 & 17.46 & 11.83 & 11.83 & 0 \\
\hline 9 & 18.46 & 18.46 & 9.38 & 9.38 & 0 \\
\hline 10 & 19.12 & 19.12 & 11.27 & 11.27 & 0 \\
\hline 11 & 14.83 & 17.37 & 7.23 & 8.96 & 1.85 \\
\hline 12 & 17.37 & 17.37 & 7.62 & 9.60 & 2.20 \\
\hline 13 & 25.81 & 26.34 & 10.80 & 11.18 & 0.43 \\
\hline 14 & 9.01 & 9.03 & 5.30 & 5.81 & 0.54 \\
\hline 15 & 9.78 & 9.78 & 3.89 & 3.89 & 0 \\
\hline 16 & 10.48 & 10.48 & 4.90 & 4.90 & 0 \\
\hline 17 & 10.63 & 12.03 & 5.10 & 6.13 & 1.10 \\
\hline 18 & 4.53 & 5.39 & 1.40 & 1.97 & 0.59 \\
\hline 19 & 4.09 & 5.09 & 1.30 & 1.99 & 0.70 \\
\hline 20 & 7.10 & 9.18 & 3.69 & 5.19 & 1.55 \\
\hline Averages & 14.83 & 15.25 & 8.61 & 9.13 & 0.567 \\
\hline
\end{tabular}

heuristic procedure. Only the flexibility index was found to be significant, with a regression coefficient of 1.84 , indicating that the advantage of the integrated heuristic grew rapidly as the flexibility index increased. When the heuristic procedure's cost increase above optimum was regressed against the same three variables, none of them was found significant.

\section{Conclusions}

The task and personnel scheduling problems have been integrated in a model that seems to offer substantial savings in the overall cost of a project. The savings come as a result of selecting a start time and labor level for each task that reduces labor cost. The integer programming optimization formulation is, however, large for realistic problems. A much more efficient heuristic approach based on dynamic programming was presented and tested. The heuristic procedure produced near-optimal solutions in terms of total cost, labor cost, and labor productivity, while providing significant savings in computation time. Yet although the heuristic solution is easily obtained for real-world problems, the optimal solution is currently impracticable.

When compared with the traditional two-stage approach, the heuristic procedure provided notable savings in total cost and labor cost, and substantial gains in labor productivity. The heuristic solution procedure yielded an $8.6 \%$ reduction in total cost compared with the traditional two-step procedure. In the test cases, this percen- tage saving tended to increase as the average number of options for start time and labor level grew. By using the heuristic procedure, labor productivity was increased in the test cases by $14 \%$ to $98 \%$. Relative to the integer programming procedure, the heuristic procedure reduced the computational time by $58 \%$.

The primary conclusion is that integrating the solutions of project task and personnel scheduling problems is both feasible and wise. Future research extensions include considering stochastic elements and sensitivity analysis of the solution. Although there are standard estimates for most construction tasks, equipment breakdowns, cost increases, and labor shortages can never be ruled out. Other reasonable follow-up efforts would be to explore refinements to the heuristic procedure presented here and to program user-friendly decision support tools for this scheduling activity.

\section{References}

[1] U.S. Department of Commerce (1990) in 1990 U.S. Industrial Outlook, International Trade Administration, U.S. Department of Commerce, Washington, D.C., pp. 5.1-5.15.

[2] Business Roundtable (1983) More Construction for the Money: Summary Report of the Construction Industry Cost Effectiveness Project, The Business Roundtable, New York.

[3] Elmaghraby, S.E. (1977) in Activity Networks: Project Planning and Control by Network Models, John Wiley and Sons, New York, pp. 173-185.

[4] Fisher, M.L. (1973) Optimal solutions of scheduling problem using Lagrange multipliers. Part I. Operations Research, 21(5), 1114-1127. 
[5] Patterson, J.H. and Huber, W.D. (1974) A horizon-varying zeroone approach to project scheduling. Management Science, 20(6), 990-998.

[6] Pritsker, A.A.B., Watters, L.J. and Wolfe, P.M. (1969) Multiproject scheduling with limited resource: a zero-one programming approach. Management Science, 16(1), 93-108.

[7] Talbot, F.B. (1982) Resource-constrained project scheduling with time-resource tradeoffs: the nonpreemptive case. Management Science, 28(10), 1197-1210.

[8] Wiest, J.D. (1963) The Scheduling of Large Projects with Limited Resources. Ph.D. Thesis, Carnegie Institute of Technology, Pittsburgh.

[9] Petrovic, R. (1968) Optimization of resource allocation in project planning. Operations Research, 16(3), 559-668.

[10] Davis, E.W. and Heidorn, G.E. (1971) An algorithm for optimal project scheduling under multiple resource constraints. Management Science, 17(12), 803-816.

[11] Stinson, J.P., Davis, E.W. and Khumawala, B.M. (1978) Multiple resource-constrained scheduling using branch and bound. AIIE Transactions, 10(3), 252-259.

[12] Talbot, F.B. and Patterson, J.H. (1978) An efficient integer programming algorithm with network cuts for solving resource constrained scheduling problems. Management Science, 24(11), $1163-1174$.

[13] Lee, S.M. and Olson, D.L. (1985) Project scheduling for multiple objectives, in Project Management: Methods and Studies, Dean, B.V. (ed.), North-Holland Publishing, Amsterdam, pp. 123-137.

[14] Baker, K.R. (1974) Scheduling a full-time workforce to meet cyclic staffing requirements. Management Science, 20(12), 15611568 .

[15] Baker, K.R. (1976) Workforce allocation in cyclical scheduling problems: a survey. Operation Research Quarterly, 27(1), 155-167.

[16] Bartholdi, J.J. (1981) A guaranteed-accuracy round-off algorithm for cyclic scheduling and set covering. Operations Research, 28(3), 501-510.

[17] Bartholdi, J.J., Orlin, J.B. and Ratliff, H.D. (1980) Cyclic scheduling via integer programs with circular ones. Operation Research, 28(5), 1074-1085.
[18] Bartholdi, J.J. and Ratliff, H.D. (1978) Unnetworks, with applications to idle time scheduling. Management Science, 24(8), 850-858.

[19] Bailey, J.E. and Field, J. (1985) Personnel scheduling with flexshift models. Journal of Operations Management, 5(3), 327-338.

[20] Emmons, H. (1985) Work-force scheduling with cyclic requirements and constraints on days off, weekends, and work stretch. IIE Transactions, 17(1), 8-16.

[21] Morris, J.G. and Showalter, M.J. (1983) Simple approaches to shift, days-off and tour scheduling problems. Management Science, 29(8), 942-950.

[22] Ozkarahan, I. and Bailey, J.E. (1988) Goal programming model subsystem of a flexible nurse scheduling support system. IIE Transactions, 20(3), 306-316.

[23] Alfares, H.K. (1991) Integrated Project Activities and Manpower Scheduling. Ph.D. dissertation, Arizona State University, Tempe.

[24] Patterson, J.H. and Roth, G.W. (1976) Scheduling a project under multiple resource constraints: a zero-one programming approach. AIIE Transactions, 8(4), 449-455.

\section{Biographies}

Hesham K. Alfares is assistant professor of Systems Engineering at King Fahd University of Petroleum and Minerals, Dhahran, Saudi Arabia. He received his BS in electrical and computer engineering from the University of California at Santa Barbara, his MS in I.E. from the University of Pittsburgh, and his Ph.D. in I.E. from Arizona State University. His current research interests include manpower scheduling and petrochemical optimization.

Dr. Bailey received his Ph.D. at Wayne State University and is a professor of Industrial Engineering at Arizona State University. He has been an active educator and researcher in personnel scheduling, integrated product and process development, energy management, and computer user satisfaction. He has published over 20 refereed papers in these areas and is co-author of the text Production Control Systems: Management, Analysis, and Design. 